\title{
Explaining Systemic Risk in Money Market Funds
}

\author{
Necmi K. Avkiran \\ School of Business, The University of Queensland, St Lucia, Australia \\ Email: n.avkiran@business.uq.edu.au
}

How to cite this paper: Avkiran, N.K. (2018) Explaining Systemic Risk in Money Market Funds. Theoretical Economics Letters, 8, 1525-1552.

https://doi.org/10.4236/tel.2018.89098

Received: February 22, 2018

Accepted: June 9, 2018

Published: June 12, 2018

Copyright $\odot 2018$ by author and Scientific Research Publishing Inc. This work is licensed under the Creative Commons Attribution International License (CC BY 4.0).

http://creativecommons.org/licenses/by/4.0/

\section{cc) (i) Open Access}

\begin{abstract}
For the first time, this study evaluates the contributions to systemic risk in the context of U.S. institutional prime money market funds (MMFs) from different sources using partial least squares structural equation modeling (PLS-SEM). The primary motivation behind this study is to trace systemic risk to its underlying sources and measure which types of relationships provide significant explanation using PLS-SEM. I illustrate the application of PLS-SEM and interpretation of results in a step-by-step manner to empower those new to PLS-SEM, and undertake robustness testing. Findings indicate that through crisis years, macroprudential indicators contribute to potential systemic risk more than prudential indicators. This suggests that macroprudential indicators that can be traced to individual MMFs market positions are more important in understanding systemic risk during crises, and further underlines the interconnectedness of markets. PLS-SEM can be used to test the explanatory power of new indicators as they emerge in an exploratory environment.
\end{abstract}

\section{Keywords}

Systemic Risk, Institutional Prime Money Market Funds, Latent Variables, Partial Least Squares Structural Equation Modeling

\section{Introduction}

As a tighter regulation of non-bank financial institutions (NbFIs) unfolds, following the global financial crisis (GFC) of 2007-2009, there is a need to monitor creation of systemic risk with new versatile tools of analysis that help explain the role of different sources of systemic risk. In a first application of partial least squares structural equation modeling (PLS-SEM) in the NbFI domain, I illustrate how PLS-SEM can be used to evaluate the creation of systemic risk among money market funds (MMFs) by starting from two different categories of 
sources of systemic risk. These are: 1) systemic risk sourced from within MMFs (prudential perspective), and 2) systemic risk sourced from MMFs' market positions (macroprudential perspective). Similarly, reference [1] underlines the importance of regulating financial institutions where a dual-focus of prudential and macroprudential perspectives is maintained. I also note that macroprudential policies are increasingly gaining priority in reforming regulation of the financial system because the Basel III Accord is inadequate in addressing spillovers into the less regulated shadow banking sector where NbFIs exist [2].

This study evaluates the contribution of each category of sources of systemic risk observed in MMFs using PLS-SEM in an effort to help regulators, managers of MMFs and investors better monitor the market. Briefly, PLS-SEM is a non-parametric approach based on OLS regression designed to maximize explained variance in latent constructs [3], e.g. systemic risk is latent because it cannot be directly observed or measured but can be observed indirectly through a number of indicators. For example, in the context of assessing systemic importance, others have also proposed indicator-based measures such as [4] on categories of size, interconnectedness and substitutability, as well as [5] size, contagion, concentration, correlation and conditions. As reference [6], p. 289, underlines "... systemic risk cannot be observed directly and must be inferred on the basis of a suitable estimation technique". PLS-SEM is considered an appropriate technique when working with composite models of prediction in exploratory research and it is robust with skewed data [7] [8].

NbFIs comprise shadow banking and their role in the GFC is well published. For example, in the period leading up to the GFC, a large proportion of financing of securitized assets was handled by NbFIs [9]. Essentially, NbFIs in shadow banking such as hedge funds, private equity funds, mutual funds, pension funds and endowments, insurance companies, finance companies and investment banks provide financial intermediation without explicit public liquidity and credit guarantees from governments. In this study, I focus on U.S. institutional prime MMFs - a type of taxable mutual fund, because prime MMFs are the major source of systemic risk among different types of MMFs and multinational corporations use MMFs to fund their day-to-day cash needs. ${ }^{1,2}$ Reference [10], p. 23, defines MMFs as a type of mutual fund that collects funds for investment in high-grade, short-term debt and bank deposits paying market rates of return; U.S. Treasury bills, certificates of deposit and commercial paper are examples of money market instruments. Furthermore, the commercial paper handled by MMFs is a major alternative to bank loans in times of crisis. Reference [11] points out that instabilities associated with MMFs were central to the GFC, and ${ }^{1}$ Other major categories of MMF are government and tax-exempt. Tax-exempt is primarily state and municipal obligations (called sub-sovereign in most countries) and their default rate is extremely low, thus not contributing to systemic risk.

${ }^{2}$ MMFs are regulated in the U.S. under the Investment Company Act of 1940 by the Securities and Exchange Commission (Rule 2a-7 underwent a major revision in 2010). Other regulators of NbFIs are Commodity Futures Trading Commission, Federal Housing Finance Agency and Bureau of Consumer Financial Protection. The Federal Reserve oversees NbFIs indicated as creating systemic risk and the Federal Deposit Insurance Corporation has resolution authority [13]. 
reference [12] outlines similar evidence from Europe. The four years in this study (2011-2014) cover the period following major reforms in 2010 implemented by the U.S. Securities and Exchange Commission (SEC), and includes years of the Eurozone sovereign debt crisis (2011-2012), as well as year 2011 (and to a lesser extent year 2013) marking the U.S. debt ceiling crisis.

Reference [14], p. 134, succinctly defines systemic risk as “...the clear and present danger that problems in financial institutions can be transmitted rapidly to other institutions or markets, inflicting damage on those institutions, their customers, and, ultimately, the economy at large." According to reference [15], systemic risk is a by-product of financial innovation and will always exist, albeit at different levels at different times. To further complicate matters, systemic risk within integrated markets is difficult to quantify and it is dynamically changing [16]. Report by the Financial Stability Board [17] refers to bank-like sources for systemic risk found among NbFIs such as maturity and liquidity transformation, imperfect risk transfer and leverage, and considers MMFs as part of the shadow banking system. As later exposed in this study, once different types of indicators of systemic risk are identified, sources and consequences of systemic risk can be explored.

The primary motivation behind this study is to illustrate how systemic risk can be traced to its underlying sources using PLS-SEM and measure which types of relationships provide significant explanation. The secondary motivation in the context of MMFs is to identify those indicators that remain statistically significant throughout the four-year study period. These motivations fit well with the main purpose of the Dodd-Frank Act of 2010 where the primary aim is one of management of systemic risk rather than its elimination.

The rest of the paper is organized as follows. Section 2 outlines the conceptual framework with a focus on regulation and systemic risk where a predictive model is developed, hypotheses posed and potential indicators identified. Section 3 discusses the PLS-SEM method and describes data. Section 4 outlines the steps in the PLS-SEM analysis and concurrently reports the findings. Section 5 is dedicated to a discussion of robustness. Finally, Section 6 offers concluding remarks.

\section{Conceptual Framework}

\subsection{Money Market Funds (MMFs) and the Emerging Regulation}

I dedicate this sub-section to a further description of MMFs and a discussion of regulation of these collective investment schemes (CIS). A general definition of MMFs is "...investment funds that seek to preserve capital and provide daily liquidity, while offering returns in line with money market rates" [18], p. 11. An alternative definition of MMFs provided by the [19], p. 277, is "A mutual fund that invests in short-term, high-grade, fixed-income securities, and seeks the highest level of income consistent with preservation of capital (i.e., maintaining a stable share price)". ${ }^{3}$ In simple terms, MMFs can be described as the main providers ${ }^{3} \mathrm{ICI}$ is the Investment Company Institute, which is a trade organization for the mutual fund industry in the U.S. ICI oversees ethical standards, advances the interests of funds, and promotes public understanding of mutual funds. 
of short-term funds to financial institutions and financial liquidity to non-financial institutions.

I continue to draw from the detailed report prepared by the Board of the International Organization of Securities Commissions [18]. The MMF industry is substantial in size, representing about U.S. $\$ 4.7$ trillion in assets under management in the first quarter of 2012; this amounts to about $1 / 5$ of the assets of the global CIS, and the U.S. and Europe represent roughly $90 \%$ of the worldwide MMF industry [18]. In the third quarter of 2015, the worldwide MMF industry stood at U.S. $\$ 4.832$ trillion. ${ }^{4}$ MMFs' share of U.S mutual fund assets at the end of 2014 was $17 \%$ and MMFs managed 23\% of U.S. businesses' short-term assets [19]. As such, MMFs provide a significant source of credit and liquidity in financial markets and they are used by retail as well as institutional investors including non-financial firms in order to diversify cash management.

The money market mutual fund industry can be categorized into four groups, namely, retail versus institutional based on clientele, and government versus prime based on portfolio risk. Institutional prime MMFs (IP-MMFs) - the focus of this study-mainly hold commercial paper and unsecured short-term claims often issued by banks, and institutional investors dominate total net assets and industry flows [20]. Institutional investors are known to respond more actively to changes in the marketplace compared to retail investors [21]. IP-MMFs represent $41.84 \%$ of all prime (taxable) funds [22]. For example, reference [22] reports that, on average, the IP-MMFs' portfolio holdings are comprised of $32 \%$ in $1^{\text {st }}$ tier commercial paper, $21 \%$ in foreign bank obligations and $15 \%$ in repurchase agreements (repos). The smaller components of average portfolio holdings are $12 \%$ each for time deposits and floating rate notes, $4 \%$ for U.S. other, $2 \%$ for U.S. Treasury, and $1 \%$ for domestic bank obligations. However, these proportions reported by iMoneyNet could be interpreted differently on the basis that some of the $1^{\text {st }}$ tier commercial paper, most of the repos and all of the time deposits are issued by banks, i.e., domestic banks play a much larger role.

The run on some MMFs in September 2008 raised concerns among the regulators as to the contribution of such funds to systemic risk in the broader financial system. For example, the announcement of Lehman Brothers' bankruptcy and ensuing losses incurred by the Reserve Primary Fund on commercial paper initiated a market run on IP-MMFs. While MMFs are not blamed for causing the GFC, they contributed to the spread and amplification of the crisis. The SEC regards MMFs as a weak link in the financial system vulnerable to sudden decrease in value that could lead to large-scale redemptions, thus contributing to systemic risk. In 2010 (the year before the analysis in this study begins), the SEC brought in major amendments to regulation of MMFs by increasing portfolio liquidity, raising credit quality, reducing maturity, introducing stress testing and enhanced transparency of fund holdings. ${ }^{5}$ Further amendments were introduced

${ }^{4}$ Source: https://www.iciglobal.org/iciglobal/research/stats/ww/ci.ww_q3_15.global (accessed on 20 January 2016).

${ }^{5}$ See SEC Rules, Money Market Fund Reform, available at

http://www.sec.gov/rules/final/2010/ic-29132.pdf. 
in July 2014 by the SEC that will come into effect on 14 October 2016 including a floating net asset value (NAV) requirement for institutional prime $\mathrm{MMFs}^{6}$ and implementation of liquidity fees and redemption gates [24] [25].

The primary risks commonly confronted by MMFs include interest rate changes, investment defaults and spread risk [26]. Yet, according to the final report by [18], the MMF industry is subject to a wider selection of vulnerabilities, which could amplify systemic risk:

- The stable net asset value (NAV of $\$ 1$ per share) conveys a false sense of safety because MMFs are also subject to credit, liquidity and interest rate risks.

- The discrepancy between the published NAV and the value of the assets arises because of amortized cost accounting and rounding methods.

- The implicit support by sponsors creates a perception of less risk in the eyes of the investors.

- The importance of ratings by credit rating agencies (CRA) could lead to reduced diligence on part of managers as well as investors.

- The first mover advantage means those investors who redeem before others will carry lesser losses.

Following from the above concerns, fifteen general recommendations have been put forward in the final report (see [18], p. 11-18). Highlights include limitations on types of assets that can be used for investment; complying with the general principle of fair value; review of valuation practices by a third party; holding a minimum amount of liquid assets; stress testing; tools to deal with substantial redemption pressures; avoiding a mechanistic reliance on external ratings; and, informing investors about the absence of a capital guarantee and the possibility of principal loss. Reference [27] notes that MMFs have already been subject to some changes including shortening of maximum maturities of investments and greater disclosure.

\subsection{Creation of Systemic Risk: Building a Predictive Model for MMFs}

Evaluating creation of systemic risk is an ongoing key regulatory activity. This task is difficult given the dynamic linkages found in the financial system among multiple counterparties, in particular, with often complex financial products found in NbFIs. To further underline the importance of this regulatory task, reference [28] expresses strong concerns about the market participants interrupting and limiting transmission of systemic risk. The authors build their arguments on the need for regulatory intervention but underline the absence of an analytical framework, in particular, how systemic risk is generated.

${ }^{6}$ However, according to reference [23], a floating NAV is misguided because a stable NAV is the main attraction of MMFs for investors and could limit access to short-term funding. The authors illustrate from a legal perspective that mandating a floating NAV is not likely to address the possibility of runs or systemic risk, and the authors maintain that systemic risk is created by investors' concerns regarding liquidity. Similarly, reference [24] maintains that a floating NAV would be less effective compared to subordinated capital buffers. 
I continue the discussion on creation of systemic risk in broad terms before returning to MMFs. Reference [28] describes a correlation between a firm's exposure to the risk of low probability adverse events and a firm's financial integrity as an intra-firm correlation. The authors also put forward the concept of an inter-firm correlation among financial firms and markets, where interaction with the intra-firm correlation can amplify transmission of localized economic shocks. An example of intra-firm correlation from the GFC is the fall in home prices-a low probability risk-causing asset-backed securities to default and loss of the integrity of institutions heavily invested in such securities. An example of inter-firm correlation is the inability to appreciate the interconnectedness among regulated banks, and say, institutions such as Bear Stearns, Lehman Brothers, AIG and other NbFIs. According to reference [28], p. 1356, "Operating together, however, these correlations create a transmission mechanism that can allow even what might appear to be a modest localized adverse economic shock to generate severe systemic consequences." Therefore, regulation that reduces such correlations can lower the monetary and social costs of financial crises. Nevertheless, the main point about regulation is to strike a fine balance between close supervision and allowing space for financial innovation because loss of diversity can create stronger channels of transmission and could expose financial systems to greater systemic risk.

Reference [29] focuses on financial innovation and resulting complexity that can lead to systemic risk. Reference [29], p. 661, identifies four sources of complexity, "1) fragmentation, 2) the creation of contingent and dynamic economic interests in the underlying assets, 3) a latent competitive tendency among different classes of investors, and 4) the lengthening of the chain separating an investor from the assets ultimately underlying its investment." Complexity contributes to information loss and stickiness (i.e., arrangements in markets that are difficult to modify) - where both could become sources of systemic risk. Briefly, the longer the chain separating an investor from an investment, the more difficult it becomes for investors to evaluate risk and value because it leads to lack of transparency.

Returning to MMFs, a study by [30] examining the risk-taking behavior of MMFs during the GFC reports findings relevant to this study. The authors highlight that contrary to pre-GFC beliefs, MMFs are not safe heavens because they take advantage of incentives to raise yields by taking on additional risk, and thus, are susceptible to runs. Reference [30] finds that 1 standard deviation rise in fund yields results in a $43 \%$ rise in annualized fund assets. Similarly, the authors find that 1 standard deviation rise in institutional prime money fund assets raises the proportion of risky funds by $3.7 \%$, underlining the more risky profile of MMFs sponsored by financial institutions. Overall, reference [30] concludes that because of the MMFs constituting an additional layer of intermediation between financial institutions and non-financial institutions (i.e., large corporations), they can create a de-stabilizing effect on financial markets. 
Reference [31] concludes that large MMFs provide liquidity to banks, thus intimately linking the shadow banking sector with regulated banking normally considered safe. It can be further argued that MMFs can be a source of systemic liquidity shock when outflows exceed inflows and lead to sale of the safest and most liquid assets. Such a scenario was observed following the bankruptcy of Lehman Brothers on 15 September 2008 when affected MMFs tried to avoid a fire sale by focusing on disposal of safe and liquid assets [20]. The primary downside of such a scenario is MMFs are left holding riskier and less liquid assets, thus weakening long-term stability. A further source of instability for MMFs is the current requirement of a stable NAV that is not guaranteed by capital buffers or insurance, instead relying on the good graces of the sponsors and strict SEC rules governing portfolio composition [32]. The requirement for a stable NAV also implies that most MMFs invest in similar portfolios, thus laying the groundwork for contagion among MMFs.

Reference [12] maintains that MMFs are riskier than previously thought and that there are discernible linkages between shadow banking and overall financial stability. Thus, there is a need for better regulation and supervision. Nevertheless, reference [32] argues that the post-GFC policymakers have a smaller number of tools at their disposal to tackle systemic risk in MMFs. Starting from the overview of linkages (channels of transmission) and complexities discussed so far, Figure 1 outlines a predictive PLS-SEM model incorporating two primary

\section{Structural model with three latent constructs} (inner model)

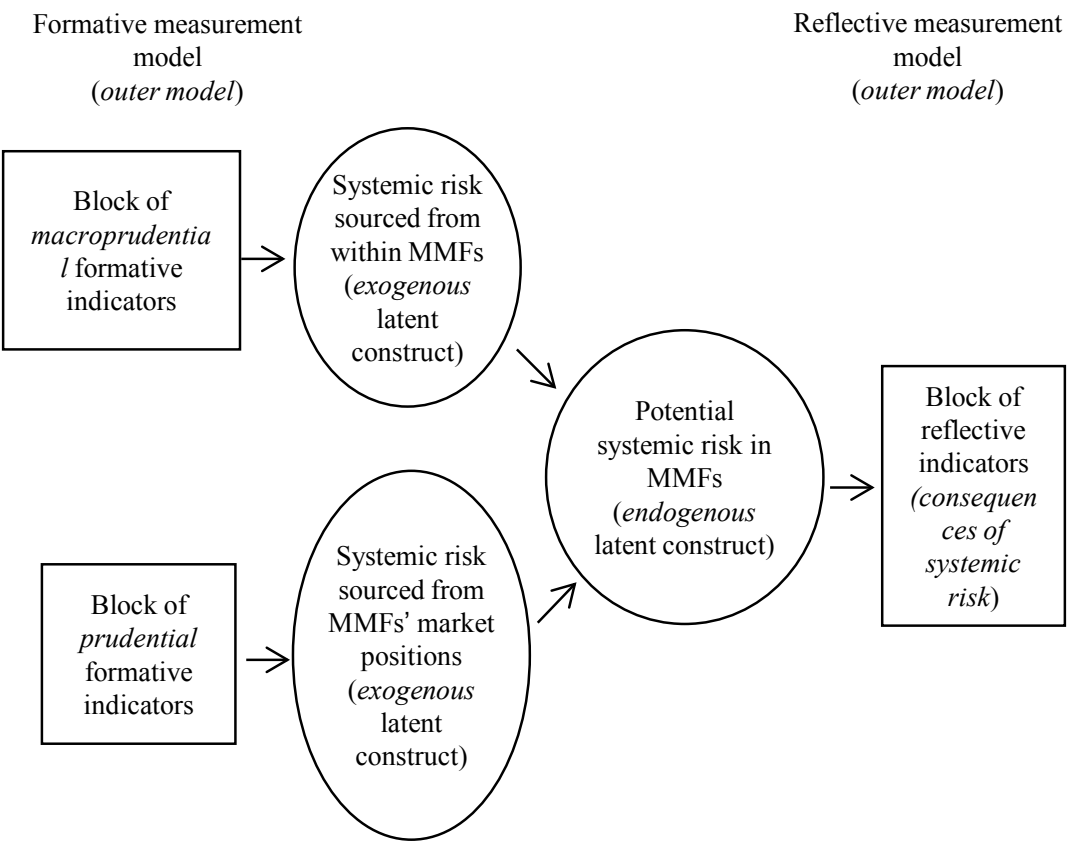

Figure 1. General Modeling Sources (formative indicators) and Consequences of Systemic Risk (reflective indicators) in Money Market Funds. Formative indicators are considered complementary and define exogenous constructs. Reflective indicators are considered interchangeable and are reflections of the endogenous construct. 
sets of sources of systemic risk in MMFs. As outlined in the introduction, I model two categories of sources of systemic risk in MMFs as latent exogenous constructs explaining the latent endogenous construct of potential systemic risk in MMFs. The so-called formative indicators define the latent exogenous constructs (i.e., sources), whereas the reflective indicators (i.e., consequences or manifestations) are defined by the latent endogenous construct (I return to PLS-SEM in more detail in sub-section 3.1. Method). Therefore, in the model outlined in Figure 1, I hypothesize the following:

$H_{1}$ : Risk sourced from intra-firm characteristics of MMFs (i.e., prudential formative indicators) makes a significant contribution to potential systemic risk observed in MMFs.

$\mathrm{H}_{2}$ : Risk sourced from individual MMFs' market positions (i.e., macroprudential formative indicators) makes a significant contribution to potential systemic risk observed in MMFs.

\section{Potential Indicators of Systemic Risk in MMFs}

This sub-section outlines the potential indicators that could be used in the predictive model depicted in Figure 1. Selection of a parsimonious set of reflective indicators (considered interchangeable) is important because they represent the manifestations of the endogenous latent construct I am trying to explain, i.e., potential systemic risk in MMFs. The following reflective indicators are considered:

1) Change in redemptions as a percent of net assets (default risk): Reference [33] reports that the majority of redemptions with prime MMFs were as a result of flight-to-liquidity during the U.S. debt ceiling crisis in 2011, and such redemptions were concentrated in funds with a higher proportion of institutional investors (focus of this study). Some of the redemptions during the U.S. debt ceiling crisis were also motivated by the opportunity to take advantage of higher repo yields by large institutional investors. Furthermore, some of these redemptions were due to exposure of MMFs to the Eurozone banks. For example, for year 2011, I measure this indicator as the difference between redemptions in the last month of the year under analysis before a crisis (e.g. July 2011) expressed as a percent of net assets and the same measure from November 2010; the latter choice is based on availability of SEC Form N-MFP on https://www.sec.gov/edgar/searchedgar/mutualsearch.html. Smaller difference suggests slow action on part of the fund management to improve liquidity, and thus, reflects a greater potential for systemic risk.

2) Credit default swap (CDS) value (default or sponsor risk): CDS is a type of swap designed to transfer the credit exposure of fixed income products among two or more parties; the buyer's CDS pays to the swap's seller until the maturity date. In theory, CDS premiums or spreads (price) can provide timely information on the creditworthiness of a financial entity or a fund. That is, higher default risk is captured in higher CDS premiums. Reference [34] demonstrates that CDS spreads based on obligations of financial institu- 
tions (e.g. investment and commercial banks) are faster than credit ratings in incorporating new information and can be useful as a regulatory tool.

For example, CDS could allow MMFs that hold bank debt to hedge against default, although such a practice is unlikely to be widespread because the cost of CDS would lower the yield, and make an MMF uncompetitive. Furthermore, CDS premiums can be a problematic measure of systemic risk for MMFs because CDS covers a period of five years, while MMFs are short-term investments and CDS premiums can be distorted by demand and supply.

Nevertheless, CDS premiums can reflect headline risk, i.e., the possibility that news adversely impact prices and/or markets. When protection is purchased, the value of the swap will rise when the CDS premium rises, reflecting deterioration in the IP-MMF's credit worthiness; the value of the swap will decline when the CDS premium drops, reflecting an improvement. When protection is sold (which creates an investment exposure for the fund), the value of the swap will rise when the CDS premium declines, reflecting an improvement in the reference entity's credit worthiness; similarly, the value of the swap will decline when the CDS premium rises, reflecting a worsening situation. The value of the swap trading is a reflection of the fund managers' risk assessment and counterparty providing the swap agreement. Therefore, I explore the availability of CDS values that net purchased and sold swaps.

For example, in 2011 and 2012, the Eurozone sovereign debt crisis is expected to have impacted on the performance of those MMFs with ownership of Eurozone banks. I expect the CDS values to be also affected by the U.S. debt ceiling crisis of 2011 but to a lesser extent in 2013 when the markets were better prepared for the follow-up U.S. debt ceiling crisis. Across the four-year study period (2011-2014), I propose to test whether CDS values are a statistically significant indicator of systemic risk in 2011-2012, and less so in 2013-2014 when the two debt crises were over.

3) Variation in gross yield around market mean (portfolio risk): Reference [35] demonstrates that gross yield can be used as an indicator of rising risk because gross yield increases as more risky securities paying higher rates are included in an MMF. MMF portfolio managers often adopt similar short-term investment strategies and thus standard deviations of funds' returns are likely to be small. Variations in returns are more likely to be dictated by the interest rates prevailing in the markets but such variations are likely to move in the same direction for most funds. Therefore, an alternative approach to capturing variation in gross yields across funds would be to measure variation around the mean, i.e., how much above or below the market mean is the gross yield for a given fund? Those funds with a gross yield much higher than the market mean are likely to carry more potential systemic risk. ${ }^{7}$

4) \% of assets held in securities deemed to be liquid within one day (liquid${ }^{7}$ Market is the full list of IP-MMFs originally downloaded from iMoneyNet's Analyzer database for each year: $2011(\mathrm{~N}=284) ; 2012(\mathrm{~N}=270) ; 2013(\mathrm{~N}=257) ; 2014(\mathrm{~N}=263)$. 
ity risk): At least $10 \%$ of assets are to be held in cash, Treasury securities, or securities that convert into cash in one business day. A drop in this ratio would reflect a rise in systemic risk. This indicator is one of the amendments to SEC Rule 2a-7 introduced in 2010.

5) \% of assets held in securities deemed to be liquid within seven days (Iiquidity risk): At least $30 \%$ of assets are to be held in cash, Treasury securities, or other government securities with remaining maturities of 60 days or less, or securities that convert into cash in five business days. Once again, a drop in this ratio would reflect a rise in systemic risk. This indicator is also one of the amendments to SEC Rule 2a-7 introduced in 2010. Other amendments to Rule 2a-7 are shown as part of the set of formative indicators.

6) Capital performance, i.e., the extent market-based value of redeemable securities significantly deviates from a NAV of \$1 (default risk): Targeting a stable NAV of $\$ 1$ (computed on amortized cost) is one of the key performance criteria expected of MMFs. When the market-based value moves away from the stable NAV of $\$ 1$, the situation is described as "breaking the buck" and safety of the capital of investors comes into doubt [20]. More specifically, Rule 2a-7 requires that a fund periodically calculates the market-based value of its portfolio (known as shadow price or mark-to-market value) and compare this to the fund's stable NAV [36]. If the difference exceeds 50 basis points, then the funds' securities are likely to be re-priced [37]. Thus, capital performance can be measured as the difference between shadow price and a fund's stable NAV of $\$ 1$. However, since the GFC, interest rates have been low, and as a result there have been no defaults or major downgrades. This means the shadow price has been either equal to the stable NAV of $\$ 1$ or very close to it, generating no significant variation. Therefore, I do not use it in this study. This indicator would be more useful in future periods, in particular when the floating NAV is taken up widely.

7) Rating of an MMF by a credit rating agency registered with SEC as a "nationally recognized statistical rating organization" (NRSRO) (portfolio risk): The majority of IP-MMFs carry a top rating so this indicator is unlikely to introduce variation into the analysis [35]. Therefore, I do not use it in this study.

In summary, a rise in reflective indicators is expected to be a consequence of increasing potential systemic risk, except indicators 1,4 and 5 where a fall indicates rising systemic risk.

I begin the selection of potential formative indicators (considered complementary) for the first exogenous latent construct representing the prudential perspective (see Figure 1, systemic risk sourced from within MMFs) by observing the major reforms introduced in 2010 in the form of amendments to the SEC Rule 2a-7 (the first four indicators):

1) Weighted average maturity (WAM, capturing sensitivity to interest rates and credit spreads): WAM is the average of the maturities of all securities held in an MMF's portfolio, weighted by each security's percentage of net as- 
sets. Maximum allowed is 60 days. Such a limit on the maximum WAM gives rise to MMFs more resilient to interest rate fluctuations that may take place in the presence of other market fluctuations, and thus reduces the chances of a run.

2) Weighted average life (WAL, capturing spread risk): WAL differs from WAM because it uses the stated final maturity date of a security. WAL is the average time for which unpaid principal remains outstanding. It is the average time that it takes for principal to be repaid, weighted by the size of each payout. Maximum allowed is 120 days. WAL limits the extent an MMF can invest in longer term securities that may expose a fund to spread risk.

3) Maximum remaining maturity on any security (liquidity risk): Maximum allowed is 397 days. Given the short-term maturity of MMFs, lengthening maximum remaining maturity indicates a higher potential for systemic risk during times of financial crisis.

4) \% of lower rated commercial paper in portfolio (credit risk): Maximum allowed is $3 \%$ of a fund's portfolio rated A2 (S \& P) /P2 (Moody's)/F2 (Fitch). In the case of IP-MMFs, second tier commercial paper is nil; therefore, I do not use this indicator.

5) Repurchase agreements as a proportion of total portfolio holdings (involvement in short-term funding): While MMFs do not fund themselves with repos, they supply funding to repo counterparties such as brokers, dealers and banks. Furthermore, repos are $100 \%$ collateralized, with the MMF holding title to the collateral and able to sell with minimal delay. During times of crisis, larger exposure to repos would raise the potential for systemic risk.

6) Foreign bank obligations as a proportion of total portfolio holdings (global exposure): This is measured as percent of total portfolio holdings. Reference [11] observes that Eurozone banks offering higher interest rates provided incentives for MMFs to take on additional risk by large positions, thus raising the potential for systemic risk.

7) Natural logarithm of net assets (size): MMF size is an approximate measure of the potential for systemic risk within the fund.

Potential formative indicators (considered complementary) for the second exogenous latent construct representing the macroprudential perspective (see Figure 1, systemic risk sourced from MMFs' market positions) are as follows:

1) Commercial paper in relation to the market (relative credit risk) ${ }^{8}$ : This is measured as the difference between commercial paper as a proportion of total portfolio holdings for a given MMF and the market mean.

2) Repurchase agreements in relation to the market (relative involvement in short-term funding): This is measured as the difference between repos as a proportion of total portfolio holdings for a given MMF and the market mean.

3) Foreign bank obligations in relation to the market (relative global exposure): This is measured as the difference between foreign bank obligations as

${ }^{8}$ According to SEC Rule 2a-7, MMFs' credit risk is limited by restricting investments to eligible securities. An eligible security must carry either a tier 1 or a tier 2 rating from an NRSRO. 
a proportion of total portfolio holdings for a given MMF and the market mean.

4) Time deposits in relation to the market (relative credit risk): This is measured as the difference between time deposits as a proportion of total portfolio holdings for a given MMF and the market mean.

5) Floating rate notes in relation to the market (relative credit risk): This is measured as the difference between floating rate notes as a proportion of total portfolio holdings for a given MMF and the market mean.

6) Net assets for an MMF as a proportion of the IP-MMF market's total net assets (relative size)

All of the formative indicators have a positive contribution to potential systemic risk, i.e., a rise in formative indicators is expected to lead to an increase in systemic risk.

\section{Method and Data}

\subsection{Method}

For the first time in the domain of NbFIs, I use the iterative OLS regression-based partial least squares structural equation modeling (PLS-SEM), also known as PLS path modeling [38] [39]. PLS-SEM is a multivariate analysis method to estimate complex cause-effect relationships with latent variables. It has been used in various disciplines such as accounting [40], management information systems [41], marketing and strategic management [42], operations management [43], supply chain management [44], and tourism [45]. The goal of the non-parametric PLS-SEM is to maximize the explained variance of endogenous latent construct(s) where the assumption of multivariate normality is relaxed. An introduction to PLS-SEM can be found in [3] [42] [46] [47], whereas reference [48] provides a step-by-step explanation of the mathematics behind its algorithm. According to reference [49], p. 270, "PLS is primarily intended for causal-predictive analysis in situations of high complexity but low theoretical information." Systemic risk in MMFs is a research environment fitting this depiction.

The distinction between formative and reflective indicators needs further explanation. For example, I try to minimize the overlap among formative indicators because they are considered complementary. That is, a change in a given formative indicator (independent of other formative indicators) can lead to a change in the associated latent construct. In multiple regression, the formative indicators are independent variables and the exogenous latent constructs illustrated in Figure 1 individually become the dependent variables. On the other hand, reflective indicators are treated as interchangeable because of the substantial overlap among them. That is, in theory a change in the endogenous latent construct would manifest itself as a change in all the reflective indicators. Thus, the endogenous latent construct depicted in Figure 1 becomes the independent variable in single regression runs where the reflective indicators individually become dependent variables. Literature review in Table 1 [47] identifies the top 
three reasons for choosing PLS-SEM as non-normal data, small sample size and presence of formative indicators. As outlined in the next sub-section, all of these conditions are found in this study's data set. Reference [5] compares PLS-SEM and covariance-based SEM.

In summary, the choice between PLS-SEM and CB-SEM will depend on the exploratory or advanced nature of the underlying theory, the types of latent constructs used, distributional nature of the data and sample size. It has also been noted that estimates from PLS-SEM and CB-SEM converge as sample size grows, as long as assumptions about distributions hold and the model is correct [50]. Those interested in further critique/rebuttal of PLS-SEM are encouraged to read [8]. In conclusion, the current study lends itself to PLS-SEM because theory is exploratory, formative and reflective indicators are used simultaneously, data are non-normal (distribution can be provided upon request) and sample size is small (see next sub-section).

\subsection{Data}

I begin with the list of IP-MMFs listed in the Analyzer database maintained by iMoneyNet to identify potential candidates for the data set [20] [26] [30] [31] [32] [35] [51]. . For each year (2011-2014), I first calculate the mean and median $1^{\text {st }}$ tier commercial paper expressed as percent of total portfolio holdings ${ }^{10}$; this emerges as a number around $30 \%$. Then I create the starting sample for each year (i.e., before data collection) where I select IP-MMFs holding at least $20 \%$ of total portfolio holdings in $1^{\text {st }}$ tier commercial paper. I focus on this sub-group in acknowledgement of the importance of commercial paper with IP-MMFs already discussed, and to work with a more consistent sample in this exploratory study. Some of the data on the indicators are hand-collected from SEC Forms such as N-MFP (Monthly Schedule of Portfolio Holdings of Money Market Funds), and others are sourced from iMoneyNet. Key dates of interest for data collection are July 2011, July 2012, September 2013, and, July 2014 (i.e., last N-MFP release before crisis deadlines; see [33], p. 17).

A brief comment on the difficulties in hand-collecting data and other issues is also merited. For example, data on \% of assets held in securities deemed to be liquid within one day (a reflective indicator) is not publicly available (established through correspondence with SEC). Furthermore, CDS values were zero for the majority of funds; therefore, I drop this indicator from the systemic risk model. In terms of correlations, two formative indicators were perfectly positively correlated; therefore, I drop foreign bank obligations as a proportion of total portfolio holdings (prudential indictor) and repurchase agreements in relation to the market (macroprudential indicator) to work around this problem in PLS-SEM. ${ }^{11}$ ${ }^{9}$ https://www.moneyfundanalyzer.com/wiasp/scripts/login/webiStart.asp

${ }^{10}$ Mean (median) values for $1^{\text {st }}$ tier commercial paper in the full sample before creation of the starting samples are: year 2011, 30.18 (30); year 2012, 28.76 (28); year 2013, 32 (31); and, year 2014, 30 (29).

${ }^{11}$ In two of the years bootstrapping failed when the perfectly correlated formative indicators were in place. 
Table 1. Summary results: Comparing PLS-SEM against GSCA.

\begin{tabular}{|c|c|c|c|c|c|c|c|c|}
\hline & & $\begin{array}{r}\text { PLS-SEN } \\
\text { Ye }\end{array}$ & $\begin{array}{l}M \text { results } \\
\text { ars }\end{array}$ & & & $\begin{array}{r}\text { GSCA } \\
\text { (robus } \\
\text { Ye }\end{array}$ & $\begin{array}{l}\text { sults } \\
\text { ness) } \\
\text { s }\end{array}$ & \\
\hline & 2011 & 2012 & 2013 & 2014 & 2011 & 2012 & 2013 & 2014 \\
\hline $\begin{array}{c}\text { Reflective } \\
\text { measurement } \\
\text { model }\end{array}$ & & & & & & & & \\
\hline $\begin{array}{l}\text { Average Variance } \\
\text { Extracted } \\
\text { (convergent } \\
\text { validity) }\end{array}$ & 0.378 & 0.376 & 0.450 & 0.407 & 0.378 & 0.375 & 0.452 & 0.417 \\
\hline $\begin{array}{l}\text { Outer loadings on } \\
\text { reflective indicators }\end{array}$ & & & & & & & & \\
\hline $\begin{array}{c}\% \text { of assets liquid in } \\
\text { seven days }\end{array}$ & $\begin{array}{c}0.812 \\
(0.073)^{\mathrm{a}}\end{array}$ & $\begin{array}{c}0.642 \\
(0.076)\end{array}$ & $\begin{array}{c}0.819 \\
(0.066)\end{array}$ & $\begin{array}{c}0.734 \\
(0.069)\end{array}$ & $\begin{array}{c}0.831 \\
(0.259)\end{array}$ & $\begin{array}{c}0.631 \\
(0.556)\end{array}$ & $\begin{array}{c}0.816 \\
(0.056)\end{array}$ & $\begin{array}{c}0.743 \\
(0.192)\end{array}$ \\
\hline $\begin{array}{l}\text { Variation in gross } \\
\text { yield }\end{array}$ & $\begin{array}{c}0.686 \\
(0.082)\end{array}$ & $\begin{array}{c}0.841 \\
(0.091)\end{array}$ & $\begin{array}{c}0.821 \\
(0.084)\end{array}$ & $\begin{array}{c}0.825 \\
(0.085)\end{array}$ & $\begin{array}{c}0.660 \\
(0.355)\end{array}$ & $\begin{array}{c}0.848 \\
(0.704)\end{array}$ & $\begin{array}{c}0.820 \\
(0.047)\end{array}$ & $\begin{array}{c}0.812 \\
(0.117)\end{array}$ \\
\hline $\begin{array}{l}\text { Change in } \\
\text { redemptions }\end{array}$ & $\begin{array}{l}-0.076 \\
(0.152)\end{array}$ & $\begin{array}{l}-0.088 \\
(0.150)\end{array}$ & $\begin{array}{c}0.078 \\
(0.151)\end{array}$ & $\begin{array}{l}-0.038 \\
(0.152)\end{array}$ & $\begin{array}{l}-0.088 \\
(0.285)\end{array}$ & $\begin{array}{l}-0.092 \\
(0.250)\end{array}$ & $\begin{array}{c}0.137 \\
(0.151)\end{array}$ & $\begin{array}{l}-0.198 \\
(0.204)\end{array}$ \\
\hline Structural model & & & & & & & & \\
\hline $\begin{array}{l}\text { Significant path } \\
\text { coefficients }\end{array}$ & $\mathrm{MP}^{\mathrm{b}}$ & MP & $\mathrm{P}^{\mathrm{c}}$ & $\mathrm{P} ; \mathrm{MP}$ & MP & $\mathrm{P} ; \mathrm{MP}$ & P; MP & $\mathrm{P} ; \mathrm{MP}$ \\
\hline $\begin{array}{c}\text { Coefficient of } \\
\text { determination }\left(R^{2}\right)\end{array}$ & 37.8 & 48.2 & 52.5 & 41.6 & 40.2 & 56.4 & 55.5 & 46.1 \\
\hline
\end{tabular}

${ }^{a}$ standard errors; ${ }^{b} \mathrm{MP}$ (macroprudential); ${ }^{\mathrm{P}}$ (prudential).

In summary, out of the five plausible reflective indicators suggested in section 2.2.1, three survive data collection; ten out of twelve potential formative indicators identified in section 2.2.1 also survive data collection.

Starting from the maximum number of indicators in this study associated with a construct (i.e., five formative indicators), the minimum sample size emerges as 45 assuming a statistical power of $80 \%$, significance level of $5 \%$ and a minimum $R^{2}$ of $50 \%$ (refer to Exhibit 1.7 in [3], p. 26) ${ }^{12}$. Thus, the actual sample sizes for $2011(\mathrm{~N}=89), 2012(\mathrm{~N}=76), 2013(\mathrm{~N}=86)$ and $2014(\mathrm{~N}=86)$, while small by CB-SEM standards, passes this test on minimum sample size. Summary statistics (details available from the corresponding author) indicate substantially non-normal data. ${ }^{13}$ Furthermore, Figure 1 shows that modeling is recursive and the research goal is predicting the endogenous construct potential systemic risk in MMFs through two exogenous constructs. That is, the context of this study accommodates the main reasons for using PLS-SEM.

${ }^{12}$ If $R^{2}$ is $25 \%$, the minimum sample size becomes 70 .

${ }^{13}$ Kolmogorov-Smirnov test reveals the majority of indicators to be non-normal across 2011-2014. For year 2011, 10 of the 13 indicators are non-normal; for 2012, 9 of the 13 indicators are non-normal; for 2013, 12 of the 13 indicators are non-normal; and for 2014, 12 of the 13 indicators are non-normal. 


\section{PLS-SEM Analysis and Findings}

I outline the evaluation procedure to be followed in PLS-SEM analysis and encourage the reader to refer to Table 3 in [46], Table 5 in [42] and [52] for further notes on the outlined procedure. Other useful references are [53] who offer a step-by-step mathematical exposition of PLS-SEM, and [54] who focuses on reporting in the second half of his chapter. I use the software SmartPLS 3 [55] for conducting the PLS-SEM analysis presented in this article. Results are reported below against each year. To reiterate, the objective of this study is to identify which indicators are significant in explaining potential systemic risk in IP-MMFs under differing circumstances.

\subsection{Reflective Measurement Model}

- Internal consistency: According to references [42] [47], composite reliability is a better measure of internal consistency because it avoids underestimation often seen with Cronbach's alpha and accommodates differences in indicator reliabilities expected by PLS-SEM. A composite reliability of 0.6 is acceptable in exploratory research [42]. Year 2011: Composite reliability is lower than 0.6 at 0.520 , casting some doubt on internal consistency of the reflective measurement model.

Year 2012: Composite reliability remains low at 0.510 .

Year 2013: Composite reliability rises above the minimum threshold at 0.641 .

Year 2014: Composite reliability drops to 0.565 .

The above suggest that one of the three indicators is not a good reflection of systemic risk.

- Indicator reliability: Outer loadings greater than 0.7 are desirable [46]. Square of this standardized outer loading represents communality, that is, how much of the variation in the indicator is explained by the endogenous construct, and 1 minus communality reveals the measurement error variance. However, reference [42] states that in exploratory research, outer loadings as low as 0.4 are acceptable. Otherwise, if less than 0.4 , the reflective indicator can be deleted (at the very least, all remaining loadings should be statistically important).

Year 2011: The highest outer loadings belongs to \% of assets liquid in seven days (0.812), followed by variation in gross yield (0.686), and change in redemptions (-0.076) (see Figure 2).

Year 2012: The order of the loadings observed in 2011 changes to variation in gross yield (0.841), \% of assets liquid in seven days (0.642), and change in redemptions (-0.088). Given that combined effects of the Eurozone sovereign debt and the U.S. debt ceiling crises were at their peak in 2012, this finding suggests that change in redemptions is not a reliable indicator of systemic risk emerging from such crises.

Year 2013: Order of the highest loadings remain as in 2012: variation in gross yield (0.821), \% of assets liquid in seven days (0.819), and change in redemptions (0.078). 


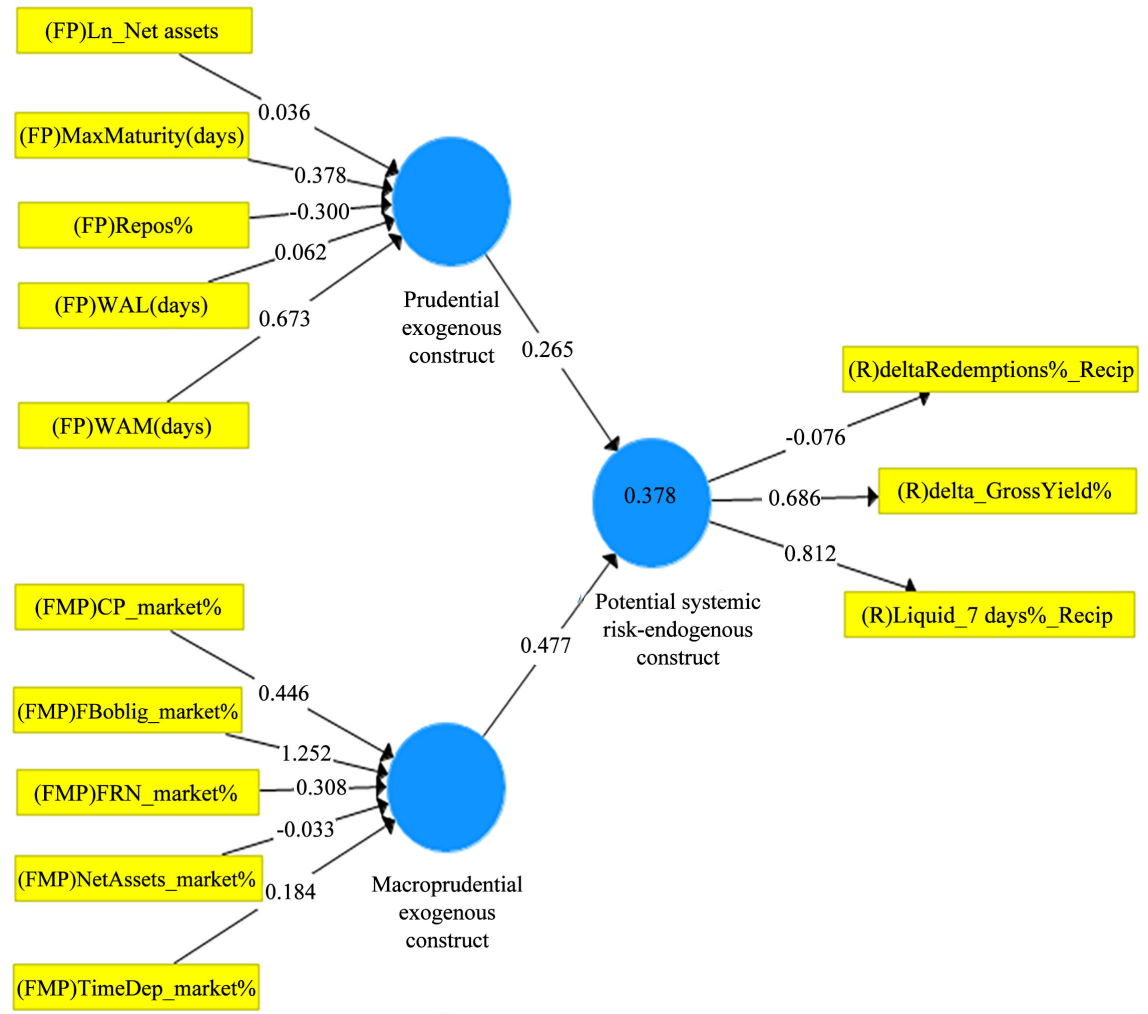

Figure 2. Model Chart from SmartPLS for Year 2011. Legend: Reflective systemic risk indicators: (R) deltaRedemptions \%, change in redemptions as a percent of net assets; (R) delta_GrossYield, variation in gross yield around market yield; (R) Liquid7 Days \%, \% of assets held in securities deemed to be liquid within seven days. Formative prudential indicators: (FP) Ln_Net assets, natural logarithm of net assets; (FP) MaxMaturity (days), maximum remaining maturity on any security; (FP) Repos \%, repurchase agreements as a proportion of total portfolio holdings; (FP) WAL (days), weighted average life; (FP) WAM (days), weighted average maturity. Formative macroprudential indicators: (FMP) CP_market \%, commercial paper in relation to the market; (FMP) FBoblig_market \%, foreign bank obligations in relation to the market; (FMP) FRN_market \%, floating rate notes in relation to the market; (FMP) NetAssets_market \%, net assets for an MMF as a proportion of the IP-MFF market's total net assets; (FMP)TimeDep_market \%, time deposits in relation to the market.

Year 2014: Order of the highest loadings remains as in 2012 and 2013: variation in gross yield (0.825), \% of assets liquid in seven days (0.734), and change in redemptions $(-0.038)$.

Across four years of analysis, the reflective indicator change in redemptions emerges as a candidate for deletion. This is likely to be the cause of low internal consistency of the reflective measurement model identified in the previous test.

- Convergent validity: Average variance extracted (AVE) greater than 0.5 is preferred; this ratio implies that greater than $50 \%$ of the variance of the indicators have been accounted. AVE is only relevant for the reflective measurement model. When examining reflective indicator loadings, it is desirable to see higher loadings in a narrow range, indicating all items are explaining the underlying latent construct, i.e., convergent validity [54]. Year 2011: AVE 
equals 0.378 , below the preferred minimum of 0.5 , suggesting less than $50 \%$ of the variance of the reflective indicators have been accounted by the latent endogenous construct.

Year 2012: AVE equals 0.376.

Year 2013: AVE rises to 0.450 .

Year 2014: AVE falls to 0.407.

In general, the above findings suggest that the endogenous construct is not strongly explaining the variance in one of the reflective indicators selected based on theoretical arguments presented in section 2.2.1. Once again, I consider deletion of the reflective indicator change in redemptions to improve AVE and other measures.

- Discriminant validity: Fornell-Larcker criterion needs to be satisfied. That is, the square root of AVE, must be greater than the correlation of the construct with all other constructs; this criterion is not applicable to formative measurement models and single-item constructs. Similarly, checking cross-loadings, all the indicators should load the highest on their associated constructs.

Year 2011: Fornell-Larcker criterion is satisfied. The reflective indicators load the highest on their associated construct, suggesting discriminant validity.

Year 2012: Fornell-Larcker criterion is satisfied. With the exception of change in redemptions, the reflective indicators load the highest on their associated construct.

Year 2013: Fornell-Larcker criterion is satisfied. The reflective indicators load the highest on their associated construct.

Year 2014: Fornell-Larcker criterion is satisfied. The reflective indicators load the highest on their associated construct with the exception of change in redemptions.

The above observations suggest that the endogenous construct is distinct from the two exogenous constructs, but once again, change in redemptions is under doubt.

\subsection{Formative Measurement Model}

- Convergent validity: Higher path coefficients linking the exogenous and endogenous constructs are preferred, implying adequate coverage by the formative indicators [54]. A substantial coefficient of determination $\left(R^{2}\right)$ is also a good indication of convergent validity.

Year 2011: The path coefficients are 0.265 from the prudential exogenous construct and 0.477 from the macroprudential exogenous construct to the endogenous construct of potential systemic risk in MMFs. $R^{2}$ stands at $37.8 \%$, or $36.4 \%$ adjusted (see Figure 2).

Year 2012: The path coefficients are 0.220 from the prudential exogenous construct and 0.600 from the macroprudential exogenous construct to the endogenous construct of potential systemic risk in MMFs. $R^{2}$ substantially rises to $48.2 \%$, or $46.8 \%$ adjusted, where the macroprudential construct continues to carry a bigger role. 
Year 2013: The path coefficients are 0.483 from the prudential exogenous construct and 0.400 from the macroprudential exogenous construct to the endogenous construct of potential systemic risk in MMFs, where the prudential construct becomes more important and the overall model becomes more balanced. $R^{2}$ continues to rise to $52.5 \%$ ( $51.3 \%$ adjusted).

Year 2014: The path coefficients are 0.393 from the prudential exogenous construct and 0.364 from the macroprudential exogenous construct to the endogenous construct of potential systemic risk in MMFs. $R^{2}$ falls to $41.6 \%$ (40.2\% adjusted).

Observations reported above suggest that as the effects of financial crises disappear after 2012, a more balanced model emerges explaining systemic risk. An alternative interpretation is to say macroprudential indicators (i.e., market-related positions of IP-MMFs) contribute more to systemic risk during crisis years.

- Multi-collinearity among indicators: When multi-collinearity exists, standard errors and thus variances are inflated. A variance inflation factor (VIF) is calculated for each of the explanatory variables in OLS regression, and VIF must be less than 5 [46], i.e., VIF represents the factor by which variance is inflated.

Statistically, VIF is the reciprocal of tolerance, $\left(1-R_{i}^{2}\right)$, where the latter is defined as the variance of a formative indicator not explained by others in the same block. A VIF of 1 means there is no correlation among the predictor variable examined and the rest of the predictors, and therefore, the variance is not inflated.

Year 2011: A VIF of 1.112 is substantially under 5, indicating absence of multi-collinearity and inflated variance.

Year 2012: VIF remains healthy at 1.084 .

Year 2013: VIF is 1.130, indicating no multicollinearity.

Year 2014: Once again, VIF is healthy at 1.279.

The above suggest that multi-collinearity is not an issue across the four years of analysis, which bodes well for the predictive model of systemic risk.

- Significance and relevance of outer weights: "Weight" is an indicator's relative contribution; "loading" is an indicator's absolute contribution. One can start with bootstrapping using 5000 sub-samples in order to check whether outer weights are significantly different from zero (the default setting is 500 subsamples and the recommended minimum by [46] is 5000). Bootstrapping involves random drawing of sub-samples from the original set of data with replacement (sub-sample size equals the original sample size). Indicators with significant outer weights are kept; otherwise, an indicator can still be kept if its outer loading, that is, its absolute contribution is greater than 0.5 . Insignificant formative indicators based on p-values (i.e., higher than 5\%) with outer loadings less than 0.5 can be removed from the model for being irrelevant. Nevertheless, eliminating formative indicators should be approached with caution because formative measurement theory expects the 
indicators to cover the domain of a construct, i.e., formative indicators are complementary.

Year 2011: Bootstrapping reveals the significance of variation in gross yield (reflective indicator), \% of assets liquid in seven days (reflective indicator), and foreign bank obligations in relation to the market (macroprudential formative indicator), and weighted average maturity (prudential formative indicator).

Year 2012: Significant indicators include variation in gross yield (reflective indicator), \% of assets liquid in seven days (reflective indicator), foreign bank obligations in relation to the market (macroprudential formative indicator), floating rate notes in relation to the market (macroprudential formative indicator), and weighted average maturity (prudential formative indicator).

Year 2013: Significant indicators include variation in gross yield (reflective indicator), \% of assets liquid in seven days (reflective indicator), foreign bank obligations in relation to the market (macroprudential formative indicator), natural logarithm of net assets (prudential formative indicator), and weighted average maturity (prudential formative indicator).

Year 2014: Significant indicators include variation in gross yield (reflective indicator), \% of assets liquid in seven days (reflective indicator), foreign bank obligations in relation to the market (macroprudential formative indicator), floating rate notes in relation to the market (macroprudential formative indicator), commercial paper in relation to the market (macroprudential formative indicator), natural logarithm of net assets (prudential formative indicator), and weighted average maturity (prudential formative indicator).

In summary, those indicators that are consistently significant across four years (crisis and non-crisis periods) are: variation in gross yield; \% of assets liquid in seven days, foreign bank obligations in relation to the market; and, weighted average maturity. At the height of the crises in 2012, floating rate notes in relation to the market becomes statistically significant.

\subsection{Structural Model}

I emphasize that if the outer models, that is, measurement models are not reliable, little confidence can be held in the inner (structural) model. Analysis of the structural model is an attempt to find evidence supporting the theoretical model, i.e., the theorized relationships between exogenous constructs and the endogenous construct.

- Predictive accuracy, coefficient of determination $\left(R^{2}\right)$ : This statistic indicates to what extent the exogenous construct(s) are explaining the endogenous construct. According to references [3] [46], 0.25 (weak), 0.50 (moderate) and 0.75 (substantial). However, unless the adjusted $R^{2}$ is used (for a formal definition, see [3], p. 199), this coefficient can be upward-biased in complex models where more paths are pointing towards the endogenous construct.

Year 2011: An adjusted $R^{2}$ of $36.4 \%$ is between weak and moderate.

Year 2012: An adjusted $R^{2}$ of $46.8 \%$ is now moderate. 
Year 2013: An adjusted $R^{2}$ of $51.3 \%$ is moderate.

Year 2014: An adjusted $R^{2}$ of $40.6 \%$ is between weak and moderate.

The above findings point to the tested indicators having moderate predictive accuracy.

- Predictive relevance $\left(Q^{2}\right)$ : This statistic is obtained by the sample re-use technique called "Blindfolding" where omission distance is set between 5 10 , where the number of observations divided by the omission distance is not an integer [42]. For example, if you select an omission distance of 7, then every seventh data point is omitted and parameters are estimated with the remaining data points. According to reference [3], omitted data points are considered missing values and replaced by mean values. Estimated parameters help predict the omitted data points and the difference between the actual omitted data points and predicted data points becomes the input to calculation of $Q^{2}$. Blindfolding is applied only to endogenous constructs with reflective indicators. If $Q^{2}$ is larger than zero, it is indicative of the path model's predictive relevance in the context of the endogenous construct and the corresponding reflective indicators.

Year 2011: $Q^{2}$ is larger than zero at 0.068 but not by a large margin, suggesting moderate predictive relevance of the endogenous construct in the modeling exercise.

Year 2012: $Q^{2}$ is larger than zero at 0.109 and a substantial improvement over year 2011.

Year 2013: $Q^{2}$ continues to rise to 0.179 , indicating path model's predictive relevance.

Year 2014: $Q^{2}$ is 0.113 , indicating a drop in path model's predictive relevance compared to year 2013 but remains an acceptable value.

- Assessing the relative impact of predictive relevance $\left(q^{2}\right): q^{2}$ effect size provides further insights to the quality of the PLS path model estimations [3]. To ascertain the impact of a given exogenous construct on the endogenous construct, the effect size is calculated by including and excluding the exogenous construct in question where the omission distance is kept identical. Effect size of 0.02 is considered small, 0.15 is moderate and 0.35 is large [3] [56].

Year 2011: The effect sizes are small at 0.0129 and 0.0429 when prudential and macroprudential exogenous constructs are excluded, respectively.

Year 2012: The effect sizes are small to moderate at 0.0011 and 0.1167 when prudential and macroprudential exogenous constructs are excluded, respectively; macroprudential shows substantial improvement over year 2011.

Year 2013: The effect sizes are small again at 0.0853 and 0.0524 when prudential and macroprudential exogenous constructs are excluded, respectively, although the relative impact of the prudential construct has substantially risen compared to the previous years.

Year 2014: The effect sizes are small at 0.0428 and 0.0293 when prudential and 
macroprudential exogenous constructs are excluded, respectively.

- Assessing the "effect sizes" $(\hat{f})$ : This statistic measures the importance of the exogenous construct(s) in explaining the endogenous construct and it re-calculates $R^{2}$ by omitting one exogenous construct at a time. Once again, effect size of 0.02 is small, 0.15 is moderate and 0.35 is large.

Year 2011: The effect sizes are 0.102 and 0.329 for prudential and macroprudential exogenous constructs, respectively. These numbers are in the moderate to large range, indicating substantial importance of the exogenous constructs in explaining the endogenous construct.

Year 2012: The effect sizes are 0.086 and 0.642 for prudential and macroprudential exogenous constructs, respectively, indicating a further improvement on macroprudential over year 2011, i.e., its importance in explaining the endogenous construct of potential systemic risk is very large.

Year 2013: The effect sizes are large at 0.435 and 0.298 for prudential and macroprudential exogenous constructs, respectively, indicating a swap in the roles of prudential versus macroprudential over the previous years.

Year 2014: The effect sizes are moderate at 0.208 and 0.179 for prudential and macroprudential exogenous constructs, respectively, but indicates a worsening situation compared to the previous year.

The above reveals that the macroprudential exogenous construct explains the endogenous construct of potential systemic risk strongly at the height of the crises. Once again, this highlights the interconnectedness of the markets and the fact that IP-MMFs' actions are not isolated.

- Significance of path coefficients: Bootstrapping is needed, following which $p$-values for the path coefficients are checked.

Year 2011: $P$-values for path coefficients are 0.095 between the prudential exogenous construct and the endogenous construct, and 0.008 for the macroprudential construct, indicating the latter as statistically significant at $5 \%$ level.

Year 2012: $P$-values for path coefficients are 0.147 between the prudential exogenous construct and the endogenous construct, and $<0.001$ for the macroprudential construct, indicating the latter as statistically significant.

Year 2013: $P$-values for path coefficients are $<0.001$ between the prudential exogenous construct and the endogenous construct, and 0.083 for the macroprudential construct, indicating the former as statistically significant.

Year 2014: $P$-values for path coefficients are 0.011 between the prudential exogenous construct and the endogenous construct, and 0.001 for the macroprudential construct, indicating both to be significant.

Overall, I notice the theorized model (see Figure 1) functions best with the macroprudential construct in years 2011 and 2012, but the prudential construct becomes equally important when the impact of the two crises wears off. That is, during a crisis, macroprudential indicators are better at explaining systemic risk. 


\section{Robustness}

In literature there are two main proposed alternatives to PLS-SEM, namely, regression based on sum scores and generalized structured component analysis (GSCA) (see comparison in [57] using Monte Carlo simulation). Regression by sum scores has recently been dismissed on the grounds that it introduces biases into parameter estimates. Reference [58] where an extensive simulated comparison was made among various SEM methods under different conditions, reveals the sum scores approach with worst parameter accuracy when loading patterns are heterogeneous (as would be found in real-world applications); the same study also finds sum scores to show the highest bias in over-estimating path coefficients in the context of measurement models and under-estimating with structural models. Similarly, reference [8]-using Monte Carlo simulation-conclude that if the indicators vary in quality and PLS-SEM is provided adequate information to estimate different weights, the emerging construct scores will be more reliable than sum scores regression in a model with only reflective indicators. That is, sum scores regression is a limited version of PLS-SEM where indicator weights in the measurement models are set as equal; as a result of equally weighted indicators, sum scores regression will outperform PLS-SEM [8]. Therefore, I do not pursue sum scores as a robustness test for PLS-SEM but focus on GSCA instead.

GSCA was introduced by [59] [60] as an alternative to PLS-SEM that provides an assessment of overall goodness-of-fit of the model under study. However, reference [61] provides a critical assessment of GSCA where it is pointed out that some of the previous findings were due to an incomplete experimental design and a mistake in the use of software. Reference [61] concludes that GSCA can provide inconsistent estimates and cannot be generally recommended as better than PLS-SEM. Despite the criticisms levelled at GSCA, I choose to apply GSCA as a robustness test because it belongs to the same family of methods, i.e., SEM. Both PLS-SEM and GSCA are variance-based methods appropriate for predictive modeling and they substitute components for factors. In terms of model specification, PLS-SEM has two equations whereas GSCA has one, and GSCA uses a global optimization function in parameter estimation with least squares (see Table 1 in [62] and [58]). As reference [63], p. 174, clearly point out “... comparison of PLS to other methods cannot and should not be applied indiscriminately." I reiterate that CB-SEM is not a viable or meaningful alternative to PLS-SEM under the conditions of the current study, i.e., small sample size, non-normal data, formative indicators and exploratory theory.

More specifically, GSCA maximizes the average or the sum of explained variances of linear composites, where latent variables are determined as weighted components or composites of observed variables. GSCA follows a global least squares optimization criterion, which in turn, is minimized to generate the model parameter estimates. GSCA is not scale-invariant and it standardizes data. GSCA is supposed to retain the advantages of PLS-SEM such as less restrictions 
on distributional assumptions (i.e., multivariate normality of observed variables is not required for parameter estimation), unique component score estimates, and avoidance of improper solutions with small samples [59] [62], while additionally providing an overall measure of model fit.

I use the web based GSCA software GeSCA (http://www.sem-gesca.org/) for robustness testing. As can be seen in Table 1, the great majority of PLS-SEM results are confirmed by GSCA. For example, AVE is near identical across four years; outer loadings are of similar magnitude in every year across the three reflective indicators; and, the coefficients of determination are also similar in their movements across four years but the magnitudes under GSCA are consistently larger. Finally, the only noticeable difference between the two approaches is the partial disagreement on significant path coefficients in years 2012-13 when the impact of the crises is manifesting itself strongly in markets.

I extend the robustness testing to what happens to some key measures of model performance when the low-loading reflective indicator change in redemptions is deleted from the endogenous construct for year 2011 (other years' PLS-SEM results are available from the corresponding author):

- Composite reliability moves from 0.520 to a much healthier 0.721 above the minimum of 0.6 .

$\circ \operatorname{AVE}$ (i.e., convergent validity) rises from 0.378 to 0.565 , and thus, into the preferred range.

- Fornell-Larcker criterion (i.e., test of discriminant validity) is satisfied more strongly.

○ VIF (i.e., multi-collinearity) shows small improvement, remaining low: 1.112 to 1.109 .

- Adjusted $R^{2}$ (i.e., predictive accuracy) is almost identical: $36.4 \%$ to $36.5 \%$.

○ Predictive relevance $\left(Q^{2}\right)$ doubles from 0.068 to a healthier 0.137 .

$\circ$ Both of the path coefficients become statistically significant at $5 \%$ level.

\section{Concluding Remarks}

In a first application of PLS-SEM to money market funds, I illustrate how the method can be used to explain systemic risk. This study evaluates the contribution of each category of sources of systemic risk (i.e., prudential and macroprudential) with the aim of helping regulators, managers of MMFs and investors better monitor the market.

Throughout 2011-2012, the macroprudential exogenous construct contributes to potential systemic risk more than the prudential exogenous construct as the impact of the crises is felt in the markets. However, this relationship is switched during 2013-2014 when the impact of Eurozone sovereign debt and US debt ceiling crises is diminished. This observation suggests that macroprudential indicators that can be traced to individual IP-MMFs (i.e., funds' market positions) are more important in understanding systemic risk during crises. This finding is sensible given the fact that MMFs provide short-term liquidity to markets and 
highlights the usefulness of PLS-SEM in the finance discipline. It also underlines the interconnectedness of markets and that IP-MMFs' actions cannot be isolated. In short, this exploratory study finds support for the two hypotheses posed at the end of Section 2.2 across four years of analysis. The indicators that emerge as consistently significant across four years are: variation in gross yield (reflective); \% of assets liquid in seven days (reflective); foreign bank obligations in relation to the market (formative macroprudential); and, weighted average maturity (formative prudential).

This study shows that other indicators of systemic risk need to be examined in future studies as more data are collected by regulators such as the SEC and become publicly available. For example, there are some contradictory positions on how to handle NAV as researchers discuss the merits and shortcomings of a floating versus stable NAV. PLS-SEM can be used to test the explanatory power of new indicators as they emerge from such discussions in the presence of secondary data that do not observe distributional assumptions.

As a final comment, selecting PLS-SEM over the more traditional CB-SEM is guided by the exploratory (PLS-SEM) versus advanced (CB-SEM) nature of the theorized model, the types of latent constructs (simultaneous inclusion of formative and reflective measurement models lends itself to PLS-SEM), distributions of the data (non-normal data favors PLS-SEM), and size of the sample (small sample sizes are problematic with CB-SEM). These are conditions often encountered in business research.

\section{Acknowledgements}

I appreciate the timely assistance provided by Kaitlin Bottock of the U.S. Securities and Exchange Commission (SEC) in interpreting various filings. I am particularly indebted to Sharon S Pichler of the SEC for sharing her extensive industry experience, and on many occasions pointing me in the right direction. Jay McLaughlin's (iMoneyNet) help in acquiring some of the data was most helpful. I also would like to thank Professor Christian M Ringle for responding to my emailed queries on PLS-SEM in a timely manner. Research assistants' help in hand-collecting the data is gratefully acknowledged (Mengxi "Maggie" Liu and Sizhe "Sid" Song). I also wish to extend my appreciation to Kam Chan and Kelvin Tan for critically reading the paper before submission.

\section{References}

[1] Acharya, V.V. (2009) A Theory of Systemic Risk and Design of Prudential Bank Regulation. Journal of Financial Stability, 5, 224-255. https://doi.org/10.1016/j.jfs.2009.02.001

[2] Valderrama, L. (2015) Macroprudential Regulation under Repo Funding. Journal of Financial Intermediation, 24, 178-199. https://doi.org/10.1016/j.jfi.2014.12.002

[3] Hair, J.F., Hult, G.T.M., Ringle, C.M. and Sarstedt, M. (2017) A Primer on Partial Least Squares Structural Equation Modeling (PLS-SEM). 2nd Edition, Sage Publications Inc., Thousand Oaks, CA. 
[4] IMF/BIS/FSB (2009) Guidance to Assess the Systemic Importance of Financial Institutions, Markets and Instruments: Initial Considerations. http://www.bis.org/publ/othp07.pdf

[5] Thomson, J.B. (2009) On Systemically Important Financial Institutions and Progressive Systemic Mitigation. Federal Reserve Bank of Cleveland Policy Discussion, Paper No. 27.

[6] López-Espinosa, G., Rubia, A., Valderrama, L. and Antón, M. (2013) Good for One, Bad for All: Determinants of Individual versus Systemic Risk. Journal of Financial Stability, 9, 287-299. https://doi.org/10.1016/j.jfs.2013.05.002

[7] Hair, J.F., Sarstedt, M., Pieper, T.M. and Ringle, C.M. (2012) The Use of Partial Least Squares Structural Equation Modeling in Strategic Management Research: A Review of Past Practices and Recommendations for Future Applications. Long Range Planning, 45, 320-340. https://doi.org/10.1016/j.lrp.2012.09.008

[8] Henseler, J., Dijkstra, T.K., Sarstedt, M., Ringle, C.M., Diamantopoulos, A., Straub, D.W., Ketchen, D.J., Hair, J.F., Hult, G.T.M. and Calantone, R.J. (2014) Common Beliefs and Reality about Partial Least Squares: Comments on Rönkkö \& Evermann (2013). Organizational Research Methods, 17, 182-209. https://doi.org/10.1177/1094428114526928

[9] Gennaioli, N., Shleifer, A. and Vishny, R.W. (2013) A Model of Shadow Banking. The Journal of Finance, 4, 1331-1363. https://doi.org/10.1111/jofi.12031

[10] Murphy, E.V. (2013) Financial Stability Oversight Council: A Framework to Mitigate Systemic Risk. Congressional Research Service, CRS Report for Congress, Washington DC, 21 May 2013.

[11] Chernenko, S. and Sunderam, A. (2014) Frictions in Shadow Banking: Evidence from the Lending Behavior of Money Market Mutual Funds. The Review of Financial Studies, 27, 1717-1750. https://doi.org/10.1093/rfs/hhu025

[12] Bengtsson, E. (2013) Shadow Banking and Financial Stability: European Money Market Funds in the Global Financial Crisis. Journal of International Money and Finance, 32, 579-594. https://doi.org/10.1016/j.jimonfin.2012.05.027

[13] Jickling, M. and Murphy, E.V. (2010) Who Regulates Whom? An Overview of U.S. Financial Supervision. Congressional Research Service, CRS Report for Congress, Washington DC, 8 December 2010.

[14] Gart, A. (1994) Regulation, Deregulation, Reregulation: The Future of the Banking, Insurance, and Securities Industries. John Wiley \& Sons, New York.

[15] Patro, D.K., Qi, M. and Sun, X. (2013) A Simple Indicator of Systemic Risk. Journal of Financial Stability, 9, 105-116. https://doi.org/10.1016/j.jfs.2012.03.002

[16] Calluzzo, P. and Dong, G.N. (2015) Has the Financial System Become Safer after the Crisis? The Changing Nature of Financial Institution Risk. Journal of Banking and Finance, 53, 233-248. https://doi.org/10.1016/j.jbankfin.2014.10.009

[17] Financial Stability Board (2013) Global Shadow Banking Monitoring Report 2013. 14 November 2013.

[18] OICU-IOSCO (2012) Policy Recommendations for Money Market Funds: Final Report. FR07/12, The Board of the International Organization of Securities Commissions.

[19] ICI Fact Book (2015) Investment Company Fact Book: A Review of Trends and Activities in the U.S. Investment Company Industry. 55th Edition, Investment Company Institute.

[20] Strahan, P.E. and Tanyeri, B. (2015) Once Burned, Twice Shy: Money Market Fund 
Responses to a Systemic Liquidity Shock. Journal of Financial and Quantitative Analysis, 50, 119-144. https://doi.org/10.1017/S0022109015000101

[21] Evans, R.B. and Fahlenbrach, R. (2012) Institutional Investors and Mutual Fund Governance: Evidence from Retail-Institutional Fund Twins. The Review of Financial Studies, 25, 3530-3571. https://doi.org/10.1093/rfs/hhs105

[22] iMoneyNet (2015) Money Fund Report. https://financialintelligence.informa.com/products-and-services/data-analysis-and-t ools/imoneynet

[23] Fisch, J. and Roiter, E. (2012) A Floating NAV for Money Market Funds: Fix or Fantasy? University of Illinois Law Review, 2012, 1003-1050. https://doi.org/10.2139/ssrn.1923828

[24] Hanson, S.G., Scharfstein, D.S. and Sunderam, A. (2015) An Evaluation of Money Market Fund Reform Proposals. IMF Economic Review, 63, 984-1023. https://doi.org/10.1057/imfer.2015.14

[25] Murphy, J., Carroll, B., Cohen, S., Katz, J. and Goldberg, J. (2015) SEC Staff Issues Money Market Fund Reform Frequently Asked Questions. Journal of Investment Compliance, 16, 47-54. https://doi.org/10.1108/JOIC-08-2015-0059

[26] Kacperczyk, M. and Schnabl, P. (2010) When Safe Proved Risky: Commercial Paper during the Financial Crisis of 2007-2009. Journal of Economic Perspectives, 24, 29-50. https://doi.org/10.1257/jep.24.1.29

[27] Elliot, D.J. (2013) Regulating Systemically Important Financial Institutions that Are Not Banks. Initiative on Business and Public Policy at Brookings, 9 May 2013, 1-23.

[28] Anabtawi, I. and Schwarcz, S.L. (2011) Regulating Systemic Risk: Towards an Analytical Framework. Notre Dame Law Review, 86, 1349-1412. https://doi.org/10.2139/ssrn.1670017

[29] Judge, K. (2012) Fragmentation Nodes: A Study in Financial Innovation, Complexity, and Systemic Risk. Stanford Law Review, 64, 657-725.

[30] Kacperczyk, M. and Schnabl, P. (2013) How Safe Are Money Market Funds? The Quarterly Journal of Economics, 128, 1073-1122. https://doi.org/10.1093/qje/qjt010

[31] Whitledge, M.D. and Winters, D.B. (2015) The Price of Liquidity: CD Rates Charged by Money Market Funds. Journal of Banking \& Finance, 54, 104-114. https://doi.org/10.1016/j.jbankfin.2015.01.016

[32] McCabe, P.E., Cipriani, M., Holscher, M. and Martin, A. (2013) The Minimum Balance at Risk: A Proposal to Mitigate the Systemic Risks Posed by Money Market Funds. In: Eberly, J. and Stock, J.H., Eds., Brookings Papers on Economic Activity, Brookings Institution Press, Baltimore, 211-256. https://doi.org/10.1353/eca.2013.0003

[33] Gallagher, E. and Collins, S. (2016) Money Market Funds and the Prospect of a US Treasury Default. Quarterly Journal of Finance, 6, 1640001-1-1640001-44. https://doi.org/10.1142/S2010139216400012

[34] Flannery, M.J., Houston, J.F. and Partnoy, F. (2010) Credit Default Swap Spreads as Viable Substitutes for Credit Ratings. University of Pennsylvania Law Review, 158, 2085-2123.

[35] McCabe, P.E. (2010) The Cross Section of Money Market Fund Risks and Financial Crises. Finance and Economics Discussion Series, Divisions of Research \& Statistics and Monetary Affairs, Federal Reserve Board, Paper No. 2010-51, 12 September 2010. https://doi.org/10.2139/ssrn.1684802

[36] ICI Research Perspective (2013) Money Market Mutual Funds, Risk, and Financial 
Stability in the Wake of the 2010 Reforms. Vol. 19, No. 1, Investment Company Institute, Washington DC.

[37] SEC (2014) Money Market Fund Reform: Amendments to Form PF. Release No. 33-9616, IA-3879; IC-31166; FR-84; File No. S7-03-13, October.

[38] Wold, H.O.A. (1982) Soft Modeling: The Basic Design and Some Extensions. In: Jöreskog, K.G. and Wold, H.O.A., Eds., Systems under Indirect Observations. Part II, North-Holland, Amsterdam, 1-54.

[39] Lohmöller, J.B. (1989) Latent Variable Path Modeling with Partial Least Squares. Physica-Verlag, Heidelberg. https://doi.org/10.1007/978-3-642-52512-4

[40] Lee, L., Petter, S., Fayard, D. and Robinson, S. (2011) On the Use of Partial Least Squares Path Modeling in Accounting Research. International Journal of Accounting Information Systems, 12, 305-328. https://doi.org/10.1016/j.accinf.2011.05.002

[41] Ringle, C.M., Sarstedt, M. and Straub, D.W. (2012) A Critical Look at the Use of PLS-SEM in MIS Quarterly. MIS Quarterly, 36, iii-xiv.

[42] Hair, J.F., Sarstedt, M., Ringle, C.M. and Mena, J.A. (2012) An Assessment of the Use of Partial Least Squares Structural Equation Modeling in Marketing Research. Journal of the Academy of Marketing Science, 40, 414-433. https://doi.org/10.1007/s11747-011-0261-6

[43] Peng, D.X. and Lai, F. (2012) Using Partial Least Squares in Operations Management Research: A Practical Guideline and Summary of Past Research. Journal of Operations Management, 30, 467-480. https://doi.org/10.1016/j.jom.2012.06.002

[44] Kaufmann, L. and Gaeckler, J. (2015) A Structured Review of Partial Least Squares in Supply Chain Management Research. Journal of Purchasing and Supply Management, 21, 259-272. https://doi.org/10.1016/j.pursup.2015.04.005

[45] do Valle, P.O. and Assaker, G. (2016) Using Partial Least Squares Structural Equation Modeling in Tourism Research: A Review of Past Research and Recommendations for Future Applications. Journal of Travel Research, 55, 695-708. https://doi.org/10.1177/0047287515569779

[46] Hair, J.F., Ringle, C.M. and Sarstedt, M. (2011) PLS-SEM: Indeed a Silver Bullet. Journal of Marketing Theory and Practice, 19, 139-151. https://doi.org/10.2753/MTP1069-6679190202

[47] Hair, J.F., Sarstedt, M., Hopkins, L. and Kuppelwieser, V.G. (2014) Partial Least Squares Structural Equation Modeling (PLS-SEM): An Emerging Tool in Business Research. European Business Review, 26, 106-121. https://doi.org/10.1108/EBR-10-2013-0128

[48] Monecke, A. and Leisch, F. (2012) semPLS: Structural Equation Modeling Using Partial Least Squares. Journal of Statistical Software, 48, 1-32.

[49] Jöreskog, K.G. and Wold, H. (1982) The ML and PLS Techniques for Modeling with Latent Variables: Historical and Comparative Aspects. In: Joreskog, K.G. and Wold, H., Eds., Systems under Indirect Observation: Causality, Structure, Prediction, Part I, Elsevier, Amsterdam, 263-270.

[50] Barosso, C., Cerrion, G.C. and Roldan, J.L. (2010) Applying Maximum Likelihood and PLS on Different Sample Sizes: Studies on SERVQUAL Model and Employee Behavior Model. In: Vinzi, V.E., Chin, W.W., Henseler, J. and Wang, H., Eds., Handbook of Partial Least Squares: Concepts, Methods and Applications, Springer-Verlag, Berlin, 427-447. https://doi.org/10.1007/978-3-540-32827-8_20

[51] Cipriani, M., Martin, A., McCabe, P. and Parigi, B.M. (2014) Gates, Fees, and Preemptive Runs. Federal Reserve Bank of New York Staff Reports, Article No. 670. 
[52] Avkiran, N.K. (2017) An In-Depth Discussion and Illustration of Partial Least Squares Structural Equation Modeling in Health Care. Health Care Management Science, 1-8. https://doi.org/10.1007/s10729-017-9393-7

[53] Tenenhaus, M., Vinzi, V.E., Chatelin, Y.-M. and Lauro, C. (2005) PLS Path Modeling. Computational Statistics \& Data Analysis, 48, 159-205. https://doi.org/10.1016/j.csda.2004.03.005

[54] Chin, W.W. (2010) How to Write Up and Report PLS Analyses. In: Esposito Vinzi, V., Chin, W.W., Henseler, J. and Wang, H., Eds., Handbook of Partial Least Squares: Concepts, Methods and Applications, Springer, Heidelberg, Dordrecht, London, New York, 655-690. https://doi.org/10.1007/978-3-540-32827-8_29

[55] Ringle, C.M., Wende, S. and Becker, J.M. (2015) SmartPLS 3. SmartPLS GmbH, Bönningstedt.

[56] Hair, J.F., Ringle, C.M. and Sarstedt, M. (2013) Partial Least Squares Structural Equation Modeling: Rigorous Applications, Better Results and Higher Acceptance. Long Range Planning, 46, 1-12. https://doi.org/10.1016/j.lrp.2013.01.001

[57] Dijkstra, T.K. and Henseler, J. (2015) Consistent partial least squares path modeling. MIS Quarterly, 39, 297-316. https://doi.org/10.25300/MISQ/2015/39.2.02

[58] Hair, J.F., Hult, G.T.M., Ringle, C.M., Sarstedt, M. and Thiele, K.O. (2017) Mirror, Mirror on the Wall: A Comparative Evaluation of Composite-Based Structural Equation Modeling Methods. Journal of the Academy of Marketing Science, 45, 616-632. https://doi.org/10.1007/s11747-017-0517-x

[59] Hwang, H. and Takane, Y. (2004) Generalized Structured Component Analysis. Psychometrika, 69, 81-99. https://doi.org/10.1007/BF02295841

[60] Hwang, H. and Takane, Y. (2014) Generalized Structured Component Analysis: A Component-Based Approach to Structural Equation Modeling. Chapman \& Hall, New York.

[61] Henseler, J. (2012) Why Generalized Structured Component Analysis Is Not Universally Preferable to Structural Equation Modeling. Journal of the Academy of Marketing Science, 40, 402-413. https://doi.org/10.1007/s11747-011-0298-6

[62] Hwang, H., Ho, M.-H. and Lee, J. (2010) Generalized Structured Component Analysis with Latent Interactions. Psychometrika, 75, 228-242.

https://doi.org/10.1007/s11336-010-9157-5

[63] Marcoulides, G.A., Chin, W.W. and Saunders, C. (2009) A Critical Look at Partial Least Squares Modeling. MIS Quarterly, 33, 171-175. https://doi.org/10.2307/20650283 